\title{
The creative business
}

DOI:

10.1080/17510694.2020.1789414

\section{Document Version}

Accepted author manuscript

Link to publication record in Manchester Research Explorer

\section{Citation for published version (APA):}

Salder, J. (2020). The creative business: Enterprise development in the arts-based creative industries. Creative Industries Journal. https://doi.org/10.1080/17510694.2020.1789414

\section{Published in:}

Creative Industries Journal

\section{Citing this paper}

Please note that where the full-text provided on Manchester Research Explorer is the Author Accepted Manuscript or Proof version this may differ from the final Published version. If citing, it is advised that you check and use the publisher's definitive version.

\section{General rights}

Copyright and moral rights for the publications made accessible in the Research Explorer are retained by the authors and/or other copyright owners and it is a condition of accessing publications that users recognise and abide by the legal requirements associated with these rights.

\section{Takedown policy}

If you believe that this document breaches copyright please refer to the University of Manchester's Takedown Procedures [http://man.ac.uk/04Y6Bo] or contact uml.scholarlycommunications@manchester.ac.uk providing relevant details, so we can investigate your claim.

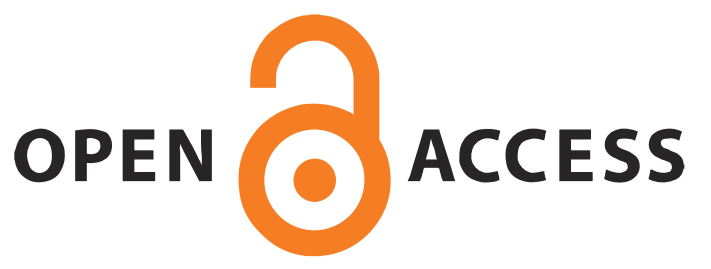




\section{The creative business: enterprise development in the arts-based creative industries}

\section{Jacob Salder}

Alliance Manchester Business School, University of Manchester, Booth Street West, Manchester, M15 6PB

jacob.salder@manchester.ac.uk

\section{Acknowledgements}

This research was supported by a grant from The Culture Capital Exchange

A previous iteration of this paper was presented at the Institute of Small Business and Entrepreneurship annual conference 2017 


\title{
The creative business: enterprise development in the arts-based creative industries
}

\begin{abstract}
The Creative Industries (CI) is a major growth sector populated by an increasing number of entrepreneurs and small enterprises. Despite its recent success, relatively little is known about how such entities practice as businesses, research too often focused upon a narrow set of subsectors. With expectations to contribute toward both economic and cultural ecosystems, such enterprises are expected to balance the rigours of business management with highly esoteric practices founded upon creative intensity and temporary systems.

This paper explores how creative firms balance business and creative practice. Focusing on the under researched Arts-based Creative Industries (ABCI), it uses a novel SME diagnostic to explore enterprise practices, dependencies and exposures in an environment of reduced funding and pressure for commercialisation. It proposes $\mathrm{ABCI}$ supplement resource limitations and demands for creative intensity through networks; techniques used by ABCI could be of value more widely to small businesses in an increasingly network-based economy. Similarly, these networks risk locking firms into unrealistic dependence on external sources of knowledge and funding with significant influence on business development.
\end{abstract}

Keywords: Creative Industries, Enterprise development, Diagnostics, Arts-based business 


\section{Introduction}

This paper discusses development practices employed by creative entrepreneurs and small enterprises within the Creative Industries (CI). SME development in the CI has become an increasingly popular topic in the past decade. Driven by continued emergence of the creative sector and its gradual recognition as a part of the mainstream economy by policy organisations (NESTA, 2013), calls for greater understanding of practice, process and impact of this sector has seen increasing exploration amongst academics.

Integral here has been analysis of the specific characteristics of the creative industries. Theories of enterprise development increasingly argue for a more heterogeneous understanding of the development process. One key element here is differentiation in practice on the basis of sector (Bamiatzi \& Kirchmaier, 2012). As a nascent sector, understandings of the development process within the creative industries are in their infancy (Schmidt et al, 2018). However, notable divergence from what might be termed standardised practice has been argued, evolving with organisational tendencies toward employee creativity, projectbased jobs, and network dependence (Bettiol \& Sedita, 2011; Hotho \& Champion, 2011; Jacobs et al, 2016; Küng, 2007).

One problem with much of this research is its own tendency to homogenise the creative sector. The range of activities classified within the creative industries represents a broad church, incorporating products and services commercial and cultural and organisations business- and artistic-focused (O'Connor, 2007; Work Foundation, 2007). Research on the creative sector has tended to examine a specific sub-sector of the industry, such as film or 
television production or computer games development, and from this extrapolate and apply practices and behaviours across the industry as a singular unit.

In this paper I examine enterprise development practice within the creative sector from the perspective of the arts-based creative industries (ABCI). Arts-based enterprise and entrepreneurs represent a very specific sub-sector of the creative industries. Fundamentally involved in high intensity original content creation for cultural consumption, $\mathrm{ABCI}$ face significant barriers in terms of the ability to commodify products, which are similarly high intensity in replication. As a result, the sub-sector is highly dependent on a public or civic infrastructure through which to explore, develop and disseminate their work. Austerity policies reducing subsidy to such infrastructure has challenged established practice within $\mathrm{ABCI}$, requiring new entrepreneurial and flexible methods of working.

Using an inductive approach, I examine ABCI development practice through the application of a diagnostic founded on core theoretical debates in small business development. The diagnostic is applied through interviews with seven separate practitioners. This is framed within a growing literature on small business heterogeneity and context-based understandings alongside distinctive interpretations of enterprise development practice within the nascent creative industries. Through the diagnostic, I examine areas of practice where ABCI collectively can be considered to perform and those where deficiencies can be identified. The analysis outlines two key areas of practice - networking and innovation - where broad models of utilisation lead to narrow, potentially path dependent tendencies. This is framed within dependence on a specific set of sponsors shaping the practices through which ABCI develop 
their business. The paper adds to a growing body of work discussing enterprise development practices within the increasingly important creative sector, alongside contributing to understanding challenges of enterprise development in an era of small business growth, large firm vertical dis-integration, and increasing network-based practices.

\section{Defining the Creative Industries: sector development and subset variation}

The Creative Industries (CI) has been the success story of the UK economy in the past decade (DMCS, 2016a; NESTA, 2016). Despite this success, the nascent and evolving nature of this industry in the context of the mainstream economy means relatively little is known about CI business practice. Increased recognition of its role and impact as part of the national economy has seen greater interest within policy circles in sponsoring CI development. Such policy is however framed within a broad enterprise support agenda, focused on small and start-up business, tending toward generic approaches without consideration of the contexts through and periods within which such firms develop (Baum et al, 2001; Bennett, 2008; Dobbs \& Hamilton, 2007; Weinzimmer, 2000).

In this section I consider the evolution of the CI and how its success emphasises need for more granular understandings of practice amongst this specific set of firms. I commence discussion with the growing debate arguing enterprises, particularly small and medium-sized, as heterogeneous entities. From this I move to theory on the development of CI, their segmentation and variation, and the role of state policy in framing how CI are interpreted.

Positioning small enterprises as heterogeneous entities 
Small enterprise development is a critical aspect of economic and regional development policy. A strong SME sector is considered integral to developing national and regional economies within Western states (Bennett, 2008), and links economic gains with social amelioration through a capacity to support long-term improvements in living standards (Parker et al, 2012).

These broad contributions run parallel to a somewhat selective interpretation of how the small business sector drives economic development. As a result, much support policy has focused on specific types of firm considered growth drivers (Anyadike-Danes et al, 2015; NESTA, 2009). Narrow interpretations miss broader outputs of this sector, in terms of job creation (Anyadike-Danes et al, 2015) and related social and environmental impact (Carter et al, 2015; McEwan et al, 2005; Vickers \& Lyon, 2014). Singular approaches have proved insufficient to broadly address firms' distinctive needs, leading to calls for more sectorally specific interventions (Bamiatzi \& Kirchmaier, 2012).

Pivotal here is interpretation of small business development and growth as complex and multidimensional (Achtenhagen et al, 2010; Leitch \& Neergard, 2010). Such growth depends on multiple variables, making the design of support an inexact science (Coad, 2009; Storey, 2011). Key questions here relate to industry-specific factors (Dobbs \& Hamilton, 2007) with distinctive routines and practices emerging within firms and groups of firms dependent on industry and operating environment. Such routines link regulation and professional practice to standardise firm behaviour (Hawawini et al, 2002; Tracey, 2011). Evolution in contexts of industry, environment and routines slowly fragment these standardised practices; as a result 
small firm development becomes a complex and integrated phenomenon (MacPherson \& Holt, 2007).

\section{Enterprise development in the creative industries}

In understanding this integrated phenomenon, the emergence of new industries and sectors provides an interesting context for inquiry. To this extent, the ongoing evolution and development of the CI offers a distinctive perspective considering both sector and firm-based contexts. The success of the CI has seen its absorption into the economic mainstream (NESTA, 2013) creating value and employment as an important driver of national economies (Cunningham \& Flew, 2013; NESTA, 2016). Here, two specific activities have compounded its development. First is the provision of added value services which drive innovation and enhance product value (de Bruin, 2005; Love et al, 2011; Verganti, 2009) particularly through processes of co-creation and personalisation (Quero \& Ventura, 2015). Second is the separate production of unique creative and cultural content (O'Connor, 2007).

CI development has been stimulated by broader macroeconomic tendencies. Ongoing vertical disintegration and related sub-contracting preferences within larger firms (Li \& Lu, 2009; Sahaym et al, 2007) have stimulated the small business sector whilst increasing demand for innovation (Baron \& Hannan, 2002; O’Regan et al, 2005). In response, such enterprises are increasingly interested in value co-creation, helping address resource limitations, and personalisation, making products and outputs distinctive (Quero \& Ventura, 2015). 
The result has seen a shifting discourse on creativity, progressing from unnecessary risk toward something critical to success (Lamper \& Germain, 2016). Integral here are elements of adaptation and innovation. For many firms, a risk is falling into competency traps preventing recognition and exploitation of new opportunities (Ahuja \& Lambert, 2001). Creativity, and the CI, help mitigate such risks, consolidating existing knowledge, products and services to generate something new or distinctive (Sapsed et al, 2007). The occurrence of creativity hinges upon individuals and organisations' willingness and capability to engage in nonroutine, experimental and often uncertain activities (Jones et al, 2015). As a result, developing a CI presents several distinct challenges.

A fundamental aspect of the creative sector is thus exposure to risk. The nascent nature, or 'newness', of the sector reinforce this risk (Stinchcombe, 1965). Functioning within an environment of experimentation and high intensity activities, failure and the ability to learn from failure are integral (Davenport, 2006). Added value elements of CI come from new value creation (Lange \& Bucker, 2013); as a result, the industry is structurally distinctive with fewer tasks in replication and greater focus on content creation. The production process within CI is highly specific, temporary and project-based (Bettiol \& Sedita, 2011). Requisite high levels of creative intensity involved within CI is not solely about content creation; it relates to the revision of practices and formation of temporary structures on a project-byproject basis (Sydow et al, 2004).

As project-based organisations, CIs depend on a diverse and specialised set of skills and knowledge; the critical component for CIs therefore occurs in human capital; employees and 
their engrained creativity and unique talents (Bridgstock, 2011; Hotho \& Champion, 2011; Küng, 2007; Lampel \& Germain, 2016) capable of responding to external change and identifying new trends (Hotho \& Champion, 2011; Preston et al, 2009). The varied and insecure nature of the sector presents several challenges in accessing, managing and retaining human capital. To compensate, the industrial ecosystem emphasises collaborative and networked models of working dependent on commissioning requisite expertise through temporary or freelance personnel (Hotho \& Champion, 2011; Küng, 2007).

Access to such specialist resource depends on forms of clustering. CIs are often argued as an urban phenomenon, density and diversity contributing to reinforce both content creation and consumption (NESTA, 2016). Concentration-agglomeration effects facilitate dissemination and sharing of ideas through structural-behavioural phenomena such as related variety, branching and co-evolution (Berg \& Hassink, 2014). Integral to this however is a firm-based commitment to continued learning and engagement, supplementing resource gaps (Chaston, 2008) and integrating key markets (Chapain \& Comunian, 2010; Lange, 2008).

Such commitment illustrates the importance of certain values and behaviours within the CI. For creative workers, financial rewards can be limited and security low. The presence of creative freedom, individuality and artistic integrity counteract such limitations (Mietzner \& Kamprath, 2013; Purnomo \& Kristiansen, 2018). Maintaining these rewards requires creative labour to be flexible, willing to do 'more-for-less' (Leadbeater, 2000). Creative workers become emotionally involved in their work, with relationships as important as commissions. 
Projects thus depend on relational governance rooted in trust-based relationship, mutual understandings, and shared values developed via repeated interaction (Zheng \& Chok, 2019).

Accommodating the integral creative and emotional autonomy of creative workers within an organisation presents many challenges. Critical here is merging organisational and individual ethos (Lamper \& Germain, 2016). Maintaining consistency is thus complex where multiple stakeholders are involved, whilst aligning an artistic or cultural bottom line with a commercial one creates additional pressures. The extent of these challenges vary significantly dependent on the type of CI.

\section{Segmentation of the Creative sector}

The CI classifies a wide set of activities and occupations; context is thus integral for both performance and practice (Kong, 2014; Oliver, 2017; Porfírio et al, 2016). This differentiation is illustrated in sub-sectoral growth performance. During the period 2011-2015, CI employment in the UK grew by $19.6 \%$. Between subsets a variance of almost 40 percentage points is seen, ranging from growth of $31 \%$ for IT-related activities to decline of $8.3 \%$ for the craft section (Table 1).

Insert 'Table 1: Creative Industries Employment Growth by Subsector 2011-2015' here

Differences between segments of the CI can be partially understood considering its heterogeneity (Flew \& Driver, 2010). Variation between practices are considerable within the 
CI. Dependence on networked models of production and iterative or project-based collaborations see working groups in constant transition (Sydow et al, 2004). As this incorporates high levels of creativity, significant variance in process and outcome emerge (Seidel, 2011) shaped further by varying levels of creative intensity specific subsets and their tasks and activities require (DCMS, 2016b).

Creative intensity provides one of the foundations of CI classification. This forms distinct groupings between sector and subset, understood as either core creative and partially creative industries (O'Connor, 2007) or core creative fields, cultural industries and creative industries and activities (Work Foundation, 2007). Such interpretation reiterates the range and diversity of activities within this sector, articulating the risk associated with generalised understandings, interpretations and responses.

The policy environment for creative industry development

Recognition of the CI as a legitimate sector of the economy has increasingly been seen in UK policy. Offering innovation and social benefits, CIs have become a critical component in addressing issues of low productivity and socio-economic polarisation (Schmidt et al, 2018). As a result, 'professionalisation' of the creative sector is a key policy objective.

Patronage of the CI runs alongside ongoing austerity policies affecting public spending and infrastructure. As a result, budget reduction in local authorities and other public agencies, such as the Arts Council, have disproportionately affected funding for certain activities within the creative sector alongside maintaining critical infrastructure and public goods on which 
specific CI are highly dependent (Harvey, 2016; Hasting et al, 2015; Jennings et al, 2017;

LGA, 2014). Such provision is key to supporting the collaborative model of evolution and the critical mass on which a successful creative sector depends (Berg \& Hassink, 2014;

Comunian et al, 2010; NESTA, 2016).

Significant growth within the creative sector and its gradual integration into the economic mainstream in both output and policy terms have seen increased levels of interest in supporting and nurturing its development. In spite of this, a shortage of research and the application of standardised models in interpreting how CI firms grow have hindered the impact of such support. Within the creative sector, notable variations from what might be termed standardised business practice can be identified, specifically around dependence on project-based systems, human capital and creativity, and delivering outputs in the face of significant resource limitations (Bridgstock, 2011; Flew \& Driver, 2010; Hotho \& Champion, 2011; Küng, 2007; Purnomo \& Kristiansen, 2018). In the face of demands to transition into fully professionalised operations, the challenges here are more significant for some subsets than others. One CI subset of interest here is Arts-based Creative Industries (ABCI). Much research on CI has focused on specific sub-sectors, but relatively little has considered the ABCI. The arts-based part of the CI has seen one of the highest recent growth rates (DCMS, 2016a). Distinctive to this set of firms is a high level of creative intensity involved in developing work, limitations in commodification potential, tendency to focus on the cultural bottom line, and narrow financing options. These challenges in commercialisation of activity run alongside ongoing decline in key state subsidisation, a critical source of income. In such a climate, funding agencies have encouraged adoption of business development models to 
stimulate long-term sustainability in arts organisations. This situation presents an interesting period in which to examine $\mathrm{ABCI}$.

Considering the relative nascent nature of the CI, further research into the practices of such firms is important. A greater range of analysis considering the constituent subsets is similarly essential. Research on the CI has to some extent fallen into the same trap as much broader economic research, where analysis based on successful firms, industries, or places has resulted in the extrapolation of models and concepts attained from studying the exception rather than the rule. This analysis similarly makes a contribution toward broader understandings of how firms' function in differing industries and contexts (Baum et al, 2001; Bennett, 2008; Dobbs \& Hamilton, 2007; Weinzimmer, 2000). Of particular significance here are changing macro-economic practices of vertical dis-integration, increased use of networked production methods enabled by technological advancements, and a shift toward entrepreneurship as part of a lifestyle choice (Li \& Lu, 2009; Sahaym et al, 2007; ERC, 2016). As an early-stage and early-adopter industry, the creative sector provides an interesting lens through which to explore small business development processes framed by a commitment to both networking and balancing business with aesthetic interests.

\section{Methodology}

Understandings of enterprise development practice in the CI are in their relative infancy, yet a mix of creative intensity and project-based working present significant diversion from standardised interpretations. Therefore, framing an understanding of the functioning of CI through more conventional models of analysis offers limited insight. Furthermore, the CI 
sector and its tendency toward collaborative, networked practices presents a model of small business management becoming more prominent; continuing trends in the vertical disintegration of production and utilisation of the benefits of communication advancement stimulating more networked practice amongst SMEs (Li \& Lu, 2009; Sahaym et al, 2007). This analysis frames CI practices in the context of previous empirical work, but extends it through adoption of a diagnostic approach allowing examination of the firm from a multideterminant perspective (Weinzimmer, 2000).

Analysis for this study was undertaken through face-to-face interviews with senior personnel (owners/managers) in seven UK-based ABCI, each involved in the development of contemporary theatre and performance work (Table 2). Each interview lasted between 90 and 120 minutes. The foundation of the inquiry was an SME diagnostic designed to examine firms from a multiple determinant perspective; this involved use of a survey framework designed for more inductive and holistic assessment of firm performance and practice (Gilman \& Salder, 2020). Diagnostics represent a novel and experimental approach to SME research with scope for compensating some of the limitations associated with conventional quantitative and qualitative methods (Fleetwood \& Hesketh, 2006; Hill \& Wright, 2001; Newby et al, 2003). Specifically, the diagnostic has potential to identify critical issues within subjects whilst compensating deficiencies of depth, breadth and impact within more deductive and rigid research approaches (Gilman \& Salder, 2020). The diagnostic was adopted for its exploratory capabilities around an inductive perspective, building an understanding through a syncretic approach which challenges rather than conforms to orthodox interpretation (MacPherson \& Holt, 2007), employing a framework exploring multiple variables framed within five key categories (Gilman \& Salder, 2020). Each category examines several variables theoretically 
and empirically associated with firm performance and capabilities, building on debates around the multiple determinants of the growth process (Baum et al, 2001; Weinzimmer, 2000).

Insert 'Table 2: Sample firm information' here

Insert 'Table 3: Diagnostic structure: categories and variables' here

\section{Exploring practice in the arts-based creative industries}

$\mathrm{ABCI}$ face several challenges, operating in a high intensity industry with limited resources, low commodification potential and declining funding. Despite this, employment in this CI subset has seen one of the most significant rises over the past five years (DCMS, 2016a). This section examines practice in the ABCI through application of a diagnostic. It considers, in the first instance, aggregate tendencies across and between subjects before looking more specifically at practices adopted on a collective basis.

Analysis on the basis of the diagnostic's key categories indicate collectively subjects adopt multiple and integrated practices, with tendencies toward flexibility and diversity. The diagnostic analysis provides a performance rating for each subject. Within four of the five defined categories - Characteristics, External Relations, Added Value, and Knowledge and 
Resource Management - collective performance was rated moderate, indicating adoption of multiple practices positively associated with small enterprise development (Gilman \& Salder, 2020). In the final of the five, Performance and Planning, collective performance was considered low, indicating potential risks and deficiencies.

Variance between firms for each of these categories was however broad. At its lowest this was found to be 8 percentage points in Knowledge \& Resource Management, whilst where highest was 43 percentage points for Added Value. This breakdown of aggregate performance within each category illustrates certain diversions between subjects in terms of practice. Lower variance in Knowledge and Resource Management and also Characteristics saw subject performance clustered singularly within the moderate range. In the remaining three categories, variance extended outside the moderate range into lower level performance for all three categories and high performance for External Relations and Added Value (Fig. 1).

Insert 'Figure 1: Practice variance across critical areas' here

Moving from category to variable, at the aggregate level ABCI displayed higher capabilities around Collaborations and Collaborative Partnerships, part of the External Relations, and around types and sources of Advice, part of the Knowledge and Resource Management. This tendency was replicated at the individual subject level. Such practices specifically relate to firm-based dependencies on mitigating resource limitations through utilising external resources offering specialist technical and operational input in both creative and business disciplines (Chaston, 2008). 
In comparison to a small number of higher capabilities displayed, the extent of lower level capabilities was more significant. Across the 44 measures examined in the diagnostic, 15 show lower level capabilities cumulatively across the sample. Amongst these, a first set were what can be termed operational measures, such as HR systems, for which firms had no formal procedures in place due to their limited size. Here the effort and cost of implementing such systems may be greater than potential returns. A second set could be termed structural measures, where variables such as age and experience indicate potential exposures. Here, liability presented by the 'newness' of the firm (Stinchcombe, 1965) is replicated in a sector seeking to reconcile unorthodox working practices with integration within the economic mainstream (Bettiol \& Sedita, 2011; Sydow et al, 2004). A final set, perhaps of greatest significance, could be termed strategic relational measures focused on critical relationships with or understandings of customers, markets, competitors and financing. Limitations amongst this set imply issues for $\mathrm{ABCI}$ in terms of developing their resilience and sustainability, with high risk of path dependence emerging through a narrow set of customers, markets and financing options.

These issues of resilience and financing represent the most critical concerns across the sample. For $\mathrm{ABCI}$ there is clear recognition of the exposure presented by dependence on narrow financing options. The Arts Council is their principal funder, and similarly principal customer, as core investor in cultural infrastructure. Ongoing austerity measures within UK Government had at the time of research seen year-on-year reductions in grant funding availability. As a result, firms were aware of the need to build a broader network and understanding of potential financing beyond grant support. The existing situation saw them 
supplementing grant dependency through either higher cost options such as credit cards and unsecured loans or donation-based approaches like crowdfunding and sponsorship. Interest in exploring other forms of investment is however set against a lack of awareness and understanding of how the investment industry worked, how to navigate it, and how to interact with potential investors.

Investor dialogue in particular raised concerns around the ability to articulate the ABCI's value proposition. Communicating this with cultural audiences and business audiences were two very distinctive tasks. Building both reputation and activity required the ability to enhance the value proposition to key customers and intermediaries with a view to both accessing increased support (funding) and progressing through a hierarchy of sponsors critical to promoting and distributing work. Focusing on building a coherent value proposition for the cultural audience prioritises the artistic dimension over the business dimension, but also frames the way ABCI think about developing their offer. This specifically focused on the demands of their narrow client base for added value and the reinforcing of project-based models of practice through key funding mechanisms.

Increased demand to achieve social objectives from arts-based funding had become more integral in developing work during the past decade. This trend has encouraged ABCI to look at innovative ways to evolve product and service offers, addressing such issues through performance work and supplementary services based on 'found' knowledge from original content research and development. Such development is supported within a principally project-based funding model, with high reliance on a single funder which requires segmenting 
work into phases and positioning projects as consecutive rather than concurrent. Whilst this model enables progressing work and developing a portfolio, such funding is not appropriate for rolling out and reprising portfolios and instead encourages continuous fresh output in a singular capacity. To operate within the rigid framework of this principal funding source, ABCI personnel continuously explore external collaborations as development partner to allow for multi-project practice. Such practice presents an ongoing challenge to ABCI in terms of continuity and value proposition.

Risk presented by project tendencies are also expressed in the continuity of project teams. Dependence upon external resource in the shape of key collaborators is high within ABCI. Projects are therefore often highly reliant on ongoing input from sub-contractors and associates during both development and delivery phases. This reliance sees not only significant levels of critical know-how siting outside of the firm, but the development of firm products enhancing external know-how. Two key exposures are created through this dynamic. The first is potential for collaborators to establish competing products or services through knowledge acquired within the collaboration. Second is the accumulation of and dependence on a form of intellectual property in external agents with potential to limit ABCI access if seeking to replicate and expand existing products and portfolios.

\section{Practice, networks and dependency: separating the creative from the business}

Aspirations for development and evolution present several challenges for CI firms. As part of an ongoing formalisation of the sector within the mainstream economy, developing business practices has become a critical consideration. Such development however needs to be 
balanced alongside maintaining the creative intensity integral to driving the added value of CI.

Managing the distinct demands of business and creative practice means the development process within CI is notably context dependent (Bamiatzi \& Kirchmaier, 2012). This is similarly a phenomenon across the CI, which incorporate a diversity of subsets of differing creative intensity and commodification potential (DCMS, 2016b; Flew \& Driver, 2010; Seidel, 2011). ABCI represent one of these subsets potentially at its most extreme, with high dependence on intensive creative production and significant limitations on commodification. Certain tendencies presented in previous studies on CI are however also identified within ABCI; amongst these are involvement in creative reconfiguration (Sapsed et al, 2007) driven by iterative, project-based modes of practice (Bettiol \& Sedita, 2011; Sydow et al, 2004) and high dependence on a rich vein of human capital (Bridgstock, 2011; Hotho \& Champion, 2011; Küng, 2007; Lampel \& Germain, 2016).

Alongside these tendencies runs the challenge of functioning in an environment with increased exposure to risk. This risk manifests in three distinct ways. Both the nascent nature of the $\mathrm{CI}$ and a development trajectory which sees $\mathrm{ABCIs}$ as creative entities before business entities means the liability of newness faced by new firms (Stinchcombe, 1965) becomes triple-edged, adding new sector and the challenges of perpetual new practices as part of a business formalisation process into the equation. Internal resource limitations see adoption of practice with high dependence on external inputs as part of the creative process (Hotho \& Champion, 2011; Küng, 2007). The distinctive and unpredictable nature of this creative 
process incorporates potential for both uncertainty and failure (Davenport, 2006; Jones et al, 2015).

Response to these challenges has counter-intuitively seen broader integration with and utilisation of external resources and networks. Content creation progressed on a project-byproject basis demands temporary collaborations (Sydow et al, 2004). Requisite expertise is therefore acquired through utilising networks of temporary or associate personnel (Hotho \& Champion, 2011; Küng, 2007; Porfírio et al, 2016). These personnel become more than subcontractors, often entering ongoing relationships with the ABCI which form mutual understandings and practices (Zheng \& Chok, 2019) in turn supplementing resource gaps (Chaston, 2008). Mutual dependency between ABCI and Associates, respectively for critical resource input and ongoing employment, create a form of 'employee-by-proxy'. This is particularly prevalent in the case of highly niche skills and capabilities not easily replicated.

Alongside ongoing creative relationships are a set of looser interactions used to supplement knowledge gaps on a more ad-hoc basis. Such relationships tend toward more business rather than creative issues. The embedded creative ties of ABCIs are therefore enhanced and supplemented by a looser form of business network.

The extent of this broadening of networks does display limits. A high dependence across $\mathrm{ABCI}$ remains on state funding sources, particularly the Arts Council. Lower levels of engagement with and understanding of potential investment beyond this source essentially see ABCI locked-in to state-based financing models. This is illustrated in the alternative forms of 
financing used, either higher cost debt-based or patronage. Dependence on the state-based model is reinforced in its position as key client and customer for ABCI products and how these are diversified.

Polarisation between these sets of networks illustrates an interesting challenge for ABCI. Firms are both active in extending networks at the same time as being bound to a narrow set of relationships. Arguably this presents a differentiation between creative practice and business practice (Lamper \& Germain, 2016). In pursuit of key inputs for creative content production, $\mathrm{ABCI}$ are consummate networkers actively developing relationships, utilising associate modes of practice, and pursuing new forms of knowledge principally for their creative content (Chaston, 2008; Hotho \& Champion, 2011; Küng, 2007). In terms of business practice, $\mathrm{ABCI}$ are establishing new relationships to guide development of their business. In certain critical areas these relationships remain static, adhering to a conventional industry model of funding and customer interaction.

The need to extend these narrow networks is recognised within ABCI, but with limited knowledge of how to progress. New modes of customer interaction are prevalent, particularly through use of social media to directly interact with potential audiences rather than relying on the embedded customer hierarchy running from Arts Council to venues to audience. Within this subsector however, the Arts Council remains the principal sponsor and direct customer. Funding conditions and practices therefore have a notable influence on the progression of business practice amongst $\mathrm{ABCI}$. 
Tendencies toward project-based working (Bettiol \& Sedita, 2011) are reinforced through principal dependence on a funding model which supports projects consecutively as opposed to concurrently. Investment is therefore focused principally on the development of products over the business itself. As a result, investment in and development of portfolios is constrained as the funding model $\mathrm{ABCI}$ are locked-in to prioritises creative content development over business development. Where business development is encouraged is through developing services using 'found' knowledge from the creative content process, particularly around social and community outcomes to enhance added value arguments for arts funding. Although this represents a diversification of practice, it similarly risks further locking $\mathrm{ABCI}$ into dependence on state-based funding whilst limiting resource focused on portfolio exploitation. Perhaps more critically is the risk of reinforcing how ABCI frame their value proposition, focused specifically on creative over business audiences and bound in to state-enforced priorities and objectives.

Emerging practices within the $\mathrm{ABCI}$ illustrate not only the distinctive nature of the creative sector, but also the scale of variation at play between its subsets. Whilst conforming with certain tendencies common in the CI, specifically around project-based working, the level of creative intensity, the limit of commodification potential, and dependence on a narrow set of financing options suggest a set of further distinctions within ABCI. Illustrating debates on the heterogeneity of practice shaped by both sector and environment (Bamiatzi \& Kirchmaier, 2012; Dobbs \& Hamilton, 2007; MacPherson \& Holt, 2007; Porfírio et al, 2016), the challenges faced by $\mathrm{ABCI}$ are at the same time concomitant with a number of the key issues faced by SMEs, particularly around resource limitations and access to finance. From this perspective, $\mathrm{ABCI}$ illustrate the role and value of networks in supplementing internal resource 
limitations. Further analysis of the practices adopted by ABCI in blending strong and loose networks and managing these through informal governance and investment processes may prove valuable to a broader set of small and start-up enterprises in an environment where network-based production is becoming commonplace.

\section{Conclusion}

This paper examines the issue of development practice used by small businesses within the Creative Industries (CI). As a nascent sector, the CI remain something of an unknown quantity in terms of firm-level development. Fusing of project-based, temporary working structures with tendencies toward non-routine activities make the CI a challenging sector for which a new set of understandings are required. Distinctive practice in the CI has its own form of variation across the sector, variation in growth trajectories and creative intensity illustrating ongoing debates on sectoral and context-based heterogeneity within SMEs (Bamiatzi \& Kirchmaier, 2012; Dobbs \& Hamilton, 2007; MacPherson \& Holt, 2007; Porfírio et al, 2016). Focusing on the Arts-based Creative Industries (ABCI), this research uses a diagnostic approach as part of an inductive analysis.

Despite rhetoric on high levels of variance in practice within the $\mathrm{CI}, \mathrm{ABCI}$ practice shows some concomitance with theories on CI development. Involvement in creative reconfiguration (O’Connor, 2007), project-based modes of practice (Bettiol \& Sedita, 2011), and dependency on human capital (Bridgstock, 2011; Hotho \& Champion, 2011; Küng, 2007; Lampel \& Germain, 2016) are all critical in the development process for ABCI. High risk generally 
associated with $\mathrm{CI}$ is also evident through the relative newness of firms, sector and emerging practices in a rapidly evolving industry being pulled into the mainstream economy.

ABCIs face several challenges here. Ongoing expansion of their networks compensates certain resource limitations (Hotho \& Champion, 2011; Küng, 2007). Further exposure to risk is thus created through dependence on external resource for critical inputs as a form of 'employee-by-proxy'. Network development is limited in the extent it addresses their key exposures; whilst extending collaboration and knowledge sources, in terms of funding and client-base there is evidence these remain narrow and dependent on a declining state-based patronage. $\mathrm{ABCI}$ therefore witness concurrent broadening and narrowing of external relations; this represents a polarisation between creative networks and business networks indicative of the relationships and industries to which ABCI are able to articulate their value.

Such challenges are partly reinforced by the funding and patronage model into which ABCI are locked, encouraging focus on project rather than business development and articulating added value through state-defined social objectives. This model may disrupt business continuity through forcing external collaboration of a secondary nature outside the remit of the $\mathrm{ABCI}$ in order to progress projects concurrently.

This paper provides a meaningful and timely insight into development practice for the CI generally and the ABCI specifically. It highlights in particular a number of specific issues $\mathrm{ABCI}$ face through the nature of its products and industrial ecosystem. Insight offered through this analysis may be of use in both the evolution of practices within $\mathrm{ABCI}$ and the 
development of policy with key funding and development organisations to stimulate more effective intervention and through this resilience amongst ABCI. Further analysis of ABCI development processes may also be useful on a longitudinal basis to generate a more comprehensive picture of the principal barriers facing this set of businesses. Considering ABCI's high level of dependence on external resources and networking, practices and methods of formal and informal relationship governance may be of interest to a broader set of small enterprises in an environment of increased network-based production. 


\section{Figures}

\section{Figure 1: Practice variance across critical areas}

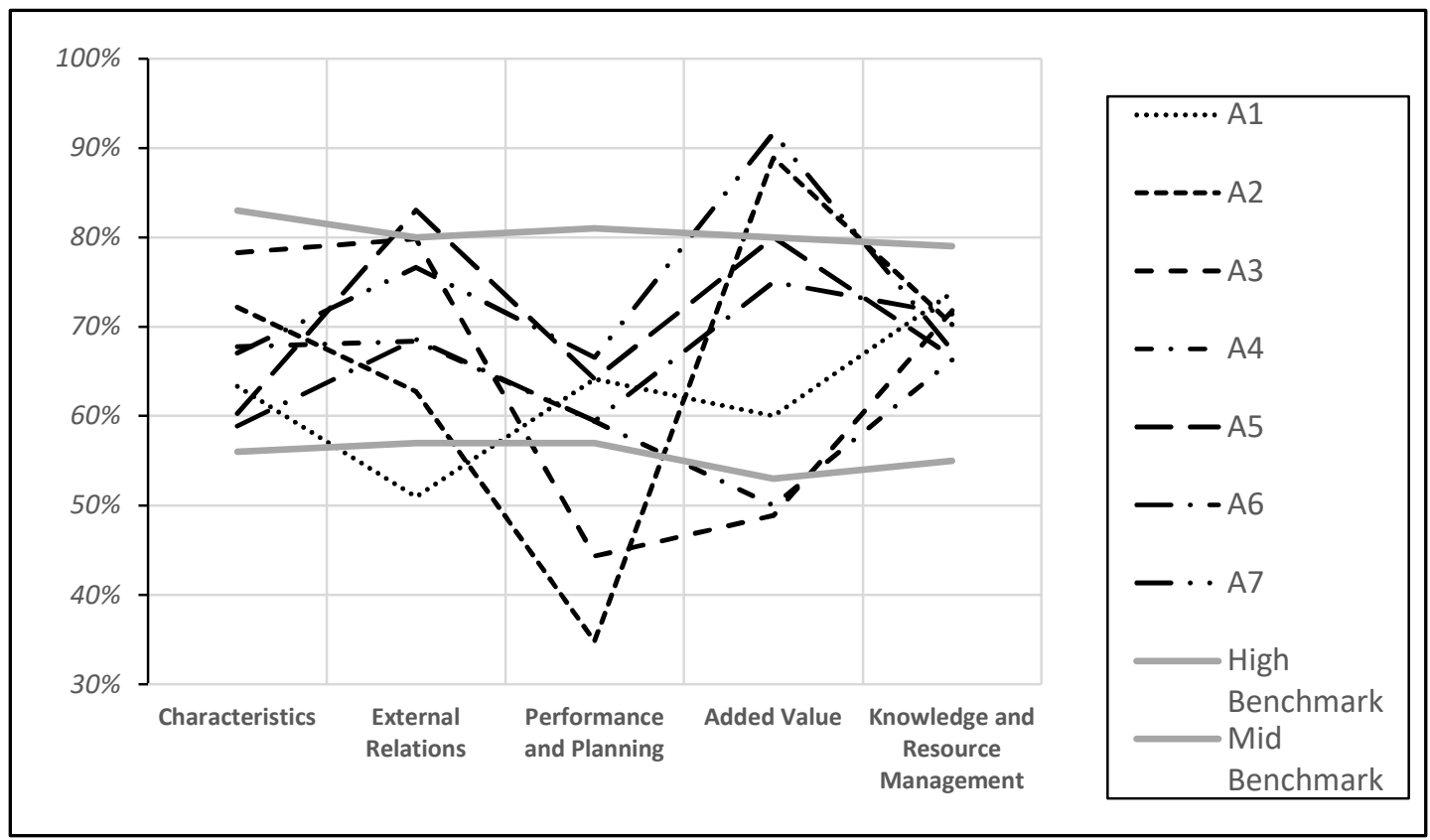

Source: Author 
$\underline{\text { Tables }}$

Table 1: Creative Industries Employment Growth by Subsector 2011-2015

\begin{tabular}{|l|l|l|l|}
\hline Creative Industry Subsector & $\underline{\mathbf{2 0 1 1}}$ & $\underline{\mathbf{2 0 1 5}}$ & $\underline{\text { \% Change }}$ \\
\hline Advertising and marketing & 470,000 & 561,000 & $19.5 \%$ \\
\hline Architecture & 121,000 & 136,000 & $11.7 \%$ \\
\hline Crafts & 105,000 & 96,000 & $-8.3 \%$ \\
\hline Design: product, graphic and fashion design & 153,000 & 197,000 & $29.5 \%$ \\
\hline Film, TV, video, radio and photography & 233,000 & 270,000 & $15.8 \%$ \\
\hline IT, software and computer services & 711,000 & 931,000 & $31.0 \%$ \\
\hline Museums, galleries and libraries & 239,000 & 118,000 & $4.0 \%$ \\
\hline Music, performing and visual arts & 113,000 & 356,000 & $29.3 \%$ \\
\hline Publishing & 276,000 & 230,000 & $-3.8 \%$ \\
\hline Creative Industries & $\mathbf{2 , 4 2 2 , 0 0 0}$ & $\mathbf{2 , 8 9 5 , 0 0 0}$ & $\mathbf{1 9 . 6 \%}$ \\
\hline
\end{tabular}

Source: DCMS, 2016a

Table 2: Sample firm information

\begin{tabular}{|l|l|l|l|l|}
\hline Subject & $\underline{\text { Formed }}$ & $\begin{array}{l}\text { Employees/ } \\
\text { Associates }\end{array}$ & $\underline{\text { Activity }}$ & $\underline{\underline{\text { Principal }}}$ \\
\hline A1 & 2012 & 12 & $\begin{array}{l}\text { Theatre venue and production } \\
\text { company }\end{array}$ & Region \\
\hline A2 & 2008 & 1 & $\begin{array}{l}\text { Contemporary theatre creation and } \\
\text { performance }\end{array}$ & Region \\
\hline A3 & 2015 & 10 & $\begin{array}{l}\text { Multi-sensory performance and } \\
\text { events }\end{array}$ & UK/EU \\
\hline A4 & 2011 & 5 & $\begin{array}{l}\text { Story-telling and theatre creation and } \\
\text { performance }\end{array}$ & UK \\
\hline A5 & 2006 & 20 & Full masked theatre performance & UK/EU \\
\hline A6 & 2005 & 9 & $\begin{array}{l}\text { Devised performance theatre } \\
\text { production }\end{array}$ & UK \\
\hline A7 & 2004 & 27 & Dance production & UK \\
\hline
\end{tabular}


Table 3: Diagnostic structure: categories and variables

\begin{tabular}{|c|l|}
\hline Category & Variables \\
\hline Characteristics & Age; Sector; Ownership; Management; Experience; Size \\
\hline $\begin{array}{c}\text { External } \\
\text { Relations }\end{array}$ & $\begin{array}{l}\text { Market distribution; International sales method; Length international } \\
\text { trading; Market conditions; Competitors; Competition strategy; } \\
\text { Competition factors; Collaborations; Collaborative partners; } \\
\text { Customer type; Supplier type }\end{array}$ \\
\hline $\begin{array}{c}\text { Performance } \\
\text { and Planning }\end{array}$ & $\begin{array}{l}\text { Growth trend; Growth expectations; Management; Strategic plan; } \\
\text { Strategic issues; Strategy ownership; Performance measures }\end{array}$ \\
\hline Added Value & $\begin{array}{l}\text { Product innovation; Process innovation; Obstacles; CSR projects; } \\
\text { Technology utilisation; Investment planning }\end{array}$ \\
\hline $\begin{array}{c}\text { Knowledge } \\
\text { and Resource } \\
\text { Management }\end{array}$ & $\begin{array}{l}\text { Investment planning; HR responsibility; HR practices; Employee } \\
\text { pay; Employee engagement; Working hours; Training budget; } \\
\text { Training days; Training providers; Skills development; Finance } \\
\text { sources }\end{array}$ \\
\hline
\end{tabular}

Source: Gilman \& Salder, 2020 


\section{$\underline{\text { References }}$}

Achtenhagen, L., Naldi, L., and Melin, L. (2010). Business growth: Do practitioners and scholars really talk about the same thing?, Entrepreneurship Theory and Practice, 34(2), 289-316.

Ahuja, G., and Lampert, C. (2001). Entrepreneurship in the large corporation: a longitudinal study of how established firms create breakthrough inventions, Strategic Management Journal, 22(6-7), 521-543.

Anyadike-Danes, M., Hart, M., and Du, J. (2015). Firm dynamics and job creation in the United Kingdom: 1998-2013, International Small Business Journal, 33(1), 12-27.

Bamiatzi, V.C., and Kirchmaier, T. (2012). Strategies for superior performance under adverse conditions: A focus on small and medium-sized high-growth firms, International Small Business Journal, 32(3), 259-284.

Baron, J.N., and Hannan, M.T. (2002). Organizational blueprints for success in high-tech start-ups: lessons from the Stanford project on emerging companies, California Management Review, 43(3), 8-36.

Baum, J.R., Locke, E.A., and Smith, K.G. (2001). A multidimensional model of venture growth, Academy of Management Journal, 44(2), 292-303.

Berg, S.H., and Hassink, R. (2014). Creative industries from an evolutionary perspective: A critical literature review, Geography Compass, 8(9), 653-664.

Bennett, R. (2008). SME policy support in Britain since the 1990: what have we learnt?, Environment and Planning C: Government and Policy, 26(2), 375-397. 
Bettiol, M., and Sedita, S.R. (2011). The role of community of practice in developing creative industry projects, International Journal of Project Management, 29(4), 468-479.

Bridgstock, R. (2011). Skills for Creative Industries Graduate Success, Education \& Training, 53(1), 9-26.

Carter, S., Mwaura, S., Ram, M., Trehan, K., and Jones, T. (2015). Barriers to ethnic minority and women's enterprise: Existing evidence, policy tensions and unsettled questions, International Small Business Journal, 33(1), 49-69.

Chapain, C., and Comunian, R. (2010). Enabling and inhibiting the creative economy: The role of the local and regional dimensions in England, Regional Studies, 44(6), 717734.

Chaston, I. (2008). Small creative industry firms: a development dilemma?, Management Decision, 46(6), 819-831.

Chaston, I., and Sadler-Smith, E. (2012). Entrepreneurial cognition, entrepreneurial orientation and firm capability in the creative industries, British Journal of Management, 23(3), 415-432.

Coad, A. (2009). The Growth of Firms: A Survey of Theories and Empirical Evidence, Cheltenham: Edward Elgar.

Comunian, R., Chapain, C., and Clifton, N. (2010). Location, location, location: exploring the complex relationship between creative industries and place, Creative Industries Journal, 3(1), 5-10.

Cunningham, S., and Flew, T. (2013) Creative industries after the first decade of debate. In Creative Industries and Urban Development (pp. 76-86). Routledge. 
Davenport, J. (2006). UK film companies: project-based organization lacking entrepreneurship and innovativeness?, Creativity and Innovation Management, 15(3), 250-257.

DCMS Department of Culture, Media and Sport (2016a). Creative Industries: focus on employment.

DCMS Department of Culture, Media and Sport (2016b). Creative Industries Economic Estimates.

de Bruin, A. (2005). Multi-Level Entrepreneurship in the Creative Industries: New Zealand's Screen Production Industry. The International Journal of Entrepreneurship and Innovation, 6(3), 143-150. https://doi.org/10.5367/0000000054662791

Dobbs, M., and Hamilton, R.T. (2007). Small business growth: recent evidence and new directions, International Journal of Entrepreneurial Behavior \& Research, 13(5), 296322.

Eisenhardt K.M. (1989). Building theories from case study research, Academic Management Review, 14(4), 532-550.

ERC Enterprise Research Centre (2016). Understanding self-employment: a report from a seminar held at Middlesex University Business School, ERC Insight Paper.

Fleetwood, S., and Hesketh, A. (2006). HRM-performance research: under-theorized and lacking explanatory power, The International Journal of Human Resource Management, 17(12), 1977-1993.

Gilman, M., and Salder, J. (2020) The role of diagnostics in engaged scholarship and SME research, The International Journal of Entrepreneurship and Innovation (in press). 
presented at the $41^{\text {st }}$ Annual Conference for the Institute of Small Business and Entrepreneurship.

Harvey, A. (2016). Funding arts and culture in a time of austerity, Arts Council England.

Hastings, A., Bailey, N., Gannon, M., Besemer, K., and Bramley, G. (2015). Coping with the cuts? The management of the worst financial settlement in living memory, Local Government Studies, 41(4), 601-621.

Hawawini, G., Subramanian, V., and Verdin, P. (2002). Is performance driven by industry or firm specific factors? A new look at the evidence, Strategic Management Journal, 24(1), 1-16.

Hill, J., and Wright, L.T. (2001). A qualitative research agenda for small to medium-sized enterprises, Marketing Intelligence \& Planning, 19(6), 432-443.

Hotho, S., and Champion, K. (2011). Small Businesses in the New Creative Industries: Innovation as a People Management Challenge, Management Decision, 49(1), 29-54.

Jacobs, S., Cambre, B., Huysentruyt, M., and Schramme, A. (2016). Multiple pathways to success in small creative businesses: The case of Belgian furniture designers. Journal of Business Research, 69(11), 5461-5466.

Jennings, M., Beirne, M., and Knight, S. (2017). Just about coping': precarity and resilience among applied theatre and community arts workers in Northern Ireland, Irish Journal of Arts Management and Cultural Policy, 4(1), 14-24.

Jones, C., Lorenzen, M., and Sapsed, J. (2015). Creative industries: A typology of change, The Oxford Handbook of Creative Industries, Oxford University Press, pp.1-51. 
Kong, L. (2014). From cultural industries to creative industries and back? Towards clarifying theory and rethinking policy, Inter-Asia cultural studies, 15(4), 593-607.

Küng, L. (2007). Does Media Management Matter? Establishing the Scope, Rationale and Future Research Agenda for the Discipline, Journal of Media Business Studies, 4(1), 2139.

Lampel, J., and Germain, O. (2016). Creative industries as hubs of new organizational and business practices, Journal of Business Research, 69(7), 2327-2333.

Lange, B. (2008). Accessing markets in creative industries - Professionalization and social-spatial strategies of culturepreneurs in Berlin, Creative Industries Journal, 1(2), $115-135$.

Lange, B., and Bürkner, H. J. (2013). Value creation in scene-based music production: the case of electronic club music in Germany, Economic Geography, 89(2), 149-169.

Leadbeater, C. (2000). Living on thin air: The new economy. London: Penguin.

Leitch, C.H.F., and Neergaard, H. (2010). Entrepreneurial and business growth and the quest for a 'comprehensive theory': Tilting at windmills?, Entrepreneurship Theory and Practice, 34(2), 249-260.

Li, B., \& Lu, Y. (2009). Geographic concentration and vertical disintegration: evidence from China, Journal of Urban Economics, 65, 294-304.

LGA Local Government Association (2014). Future funding outlook 2014: Funding outlook for Councils to 2019/20.

Love, J.H., Roper, S., and Bryson, J. (2011). Knowledge, openness, innovation and growth in UK business services, Research Policy, 40(10), 1438-1452. 
Macpherson, A., and Holt, R. (2007). Knowledge, learning and small firm growth: a systematic review of the evidence, Research Policy, 36(2), 172-192.

McEwan, C., Pollard, J., and Henry, N. (2005). The 'global' in the city economy: Multicultural economic development in Birmingham, International Journal of Urban and Regional Research, 29(4), 916-933.

Mietzner, D., and Kamprath, M. (2013). A competence portfolio for professionals in the creative industries, Creativity and Innovation Management, 22(3), 280-294.

NESTA (2009). The Vital 6 per cent, www.nesta.org.uk.

NESTA (2013) A Manifesto for the Creative Economy, www.nesta.org.uk NESTA (2016). The geography of creativity in the UK: creative clusters, creative people and creative networks, www.nesta.org.uk..

Newby, R., Watson, J., and Woodliff, D. (2003). Using focus groups in SME research: the case of owner-operator objectives, Journal of Developmental Entrepreneurship, 8(3), 237.

O'Connor, J. (2007). The Cultural and Creative Industries: A Review of the Literature. London: Creative Partnerships, Arts Council England.

O’Regan, N., Ghobadian, A., and Sims, M. (2006). Fast tracking innovation in manufacturing SMEs, Technovation, 26(2), 251-261.

Oliver, J.J. (2017). Exploring industry level capabilities in the UK creative industries, Creative Industries Journal, 10(1), 75-88.

Parker, S.C., Congregado, E., and Golpe, A.A. (2012). Is entrepreneurship a leading or lagging indicator of the business cycle? Evidence from UK self-employment data, International Small Business Journal, 30(7), 736-753. 
Porfírio, J.A., Carrilho, T., and Mónico, L.S. (2016). Entrepreneurship in different contexts in cultural and creative industries. Journal of Business Research, 69(11), 51175123.

Preston, P., Kerr, A., and Cawley, A. (2009). Innovation and Knowledge in the Digital Media Sector - An Information Economy Approach, Information, Communication \& Society, 12(7), 994-1014.

Purnomo, B.R. and Kristiansen, S. (2018). Economic reasoning and creative industries progress, Creative Industries Journal, 11(1), 3-21.

Quero, M.J., and Ventura, R. (2015). The role of balanced centricity in the Spanish creative industries adopting a crowd-funding organisational model, Journal of Service Theory and Practice, 25(2), 122-139.

Sahaym, A., Steensma, H.K., and Schilling, M.A. (2007). The influence of information technology on the use of loosely coupled organizational forms: An industry-level analysis, Organizational Science, 18(5), 865-880.

Sapsed, J., Grantham, A., and DeFillippi, R. (2007). A Bridge over Troubled Waters: Bridging Organisations and Entrepreneurial Opportunities in Emerging Sectors, Research Policy, 36(9), 1314-1334.

Schmidt, S., Schreiber, D., Bohnenberger, M.C. and Pinheiro, C.M.P. (2018). Strategic design in small creative industry firms, Creative Industries Journal, 11(3), 306-321.

Seidel, S. (2011). Toward a theory of managing creativity-intensive processes: a creative industries study, Information Systems and e-Business Management, 9(4), 407-446. Stinchcombe, A. L. (1965). Social structure and organizations, In J. G. March (Ed.), Handbook of Organizations, Chicago: Rand McNally, pp. 142-193. 
Storey, D.J. (2011). Optimism and chance: The elephants in the entrepreneurship room, International Small Business Journal, 29(4), 303-321.

Sydow, J., Lindkvist, L., and DeFillippi, R. (2004). Project-based organizations, embeddedness and repositories of knowledge: editorial, Organization Studies, 25(9), 1475-1489.

Tracey P (2011). Entrepreneurship and neo-institutional theory. In J. Mole \& M. Ram (Eds) Perspectives in Entrepreneurship: A Critical Approach, Basingstoke: Palgrave, pp.93-106.

Verganti, R. (2009). Design-Driven Innovation. Boston, MA: Harvard Business Press.

Vickers, I., and Lyon, F. (2014). Beyond green niches? Growth strategies of environmentally-motivated social enterprises, International Small Business Journal, 32(4), 449-470.

Weinzimmer, L.G. (2000). A replication and extension of organisational growth determinants, Journal of Business Research, 48(1), 35-41.

Work Foundation (2007). Staying ahead: the economic performance of the UK's creative industries.

Zheng, C., \& Chok, J. I. (2019). Institutional contradictions and community emergence: An examination of institutional entrepreneurship in the popular music industries context. The International Journal of Entrepreneurship and Innovation, 20(1), 50-64. 